This is an Accepted Manuscript of an article published by Taylor \& Francis in Architectural Engineering and Design Management on 16/06/16, available online:

https://www.tandfonline.com/doi/full/10.1080/17452007.2016.1195332 


\title{
Approaches, Drivers and Motivators of Health and Safety Self-Regulation in the Nigerian Construction Industry: A Scoping Study
}

\author{
Nnedinma Umeokafor \\ Department of Built Environment, Faculty of Architecture, Computing \& Humanities, \\ University of Greenwich, London, UK
}

\begin{abstract}
The premise that the Nigerian construction industry is unregulated in terms of health and safety $(H \& S)$ is contested in this scoping study, evidencing that the industry is self-regulated and the determinants poorly understood. H\&S self-regulatory approaches in the industry and key drivers and motivators were identified, assessed and explained through literature review, questionnaire survey and interviews. Contractors were found to mostly self-regulate in terms of H\&S because of normative related factors. There was a significant difference between large construction firms and medium-sized firms and between large construction firms and small-sized construction firms on the factor 'it is a duty to adopt H\&S programs'. Additionally, client-led H\&S self-regulation was perceived to be more effective than mandatory industry H\&S self-regulation, with a relationship existing among the two, and the size of firms. Organisational values influenced the decision to self-regulate in large-scale construction contractors compared to small and medium scale contractors. While the study draws attention to H\&S self-regulation in the Nigerian construction industry, it also provides evidence of alternative means to improve H\&S in Nigeria in the absence of adequate state involvement. Although a scoping study, the results provide a unique insight into the Nigerian construction industry and attitudes to H\&S.
\end{abstract}

Keywords: contractors, co-regulation, health and safety (H\&S), Nigeria, selfregulation

\section{INTRODUCTION}

Despite the hazardous nature of construction activities, construction sites and activities are not covered by the existing health and safety (H\&S) legislation in Nigeria - Factories Act F1 LFN 2004 (Diugwu et al. 2012; Idoro 2008, 2011). Consequently, Diugwu et al. (2012) and Idoro $(2008,2011)$ conclude that the Nigerian construction industry is unregulated (also see Umeokafor et al. 2014). However, based on the concept of self-regulation (Gunningham 2011; Havinga 2006; King \& Lenox 2000) the Nigerian construction industry is not unregulated, rather it is self-regulated in various forms (Umeokafor \& Isaac 2015). H\&S self-regulation is the practice where an industry, organisation or individual develops, adopts and administers policies, standards and programs to promote the safety, health and welfare of workers and those that will be indirectly or directly affected by the activities. This is with little or no external involvement. That the Nigerian construction industry is self-regulated is supported by, for example, the adoption of H\&S legislation and standards from developed countries by construction contractors where the implementation, enforcement and monitoring are at the discretion of the adopters 
(Idoro 2008, 2011; Tanko \& Anigbogu 2012). This is in line with the description of self-regulation and can be either pure self-regulation (Gunningham 2011) or enforced self-regulation (Fairman \&Yapp 2005). When an industry such as oil and gas in Nigeria specifies standards and enforces them, this is a form of industry selfregulation (Umeokafor \& Isaac 20015). There is also a case demonstrating client-led self-regulation in Nigeria by Umeokafor and Isaac (2015). However, what is poorly understood are the drivers and motivators of H\&S self-regulation in the Nigerian construction industry, especially because of the challenges that the context of Nigeria present. The extent that these drivers and motivators impact on the decision-making process of the various categories (as per size) of construction contractors in Nigeria remains poorly understood. Idoro (2011) notes the importance of stakeholders in the industry having a good understanding of the contributions of contractors to improving $\mathrm{H} \& \mathrm{~S}$ according to their categories. Examining the contractors in terms of size stems from evidence in studies by Vickers et al. (2005) and Windapo and Jegede (2013) where the contractors' involvement in H\&S and their H\&S record varies due to size and characteristics of the firm. Small firms are sometimes disadvantaged by selfregulation. Consequently, regulatory strategies should factor in inter alia these differences (Wright 1998). Self-regulation differs from country to country (Hutter 2006) and the regulation of H\&S can be complex (Kingstin-Howlett 2001). The various self-regulatory approaches make the regulatory environment of Nigeria complex. Therefore, there is the need to identify, assess and hence better understand the H\&S self-regulatory approaches in Nigeria. The research reported in this paper addresses all the above. The findings may help academics and interested policymakers at the industry level to improve regulation of H\&S, getting the industry (more contractors) to self-regulate. The work also offers insight into the concept of self-regulation in developing countries.

\section{LITERATURE SURVEY}

\section{Relating health and safety challenges to the size of firms}

The construction industry continues to be hazardous and evidence in studies (Idoro 2011; Windapo \& Jegede 2013) shows the construction H\&S record of developing countries to be worse than developed countries. For example, a recent study of Nigerian contractors shows that employees of large sized multinationals have witnessed one fatality while employees of small and medium enterprise (SMEs) contractors have witnessed 22 fatalities (Windapo \& Jedede 2013). This is in addition to poor H\&S practices mostly found in SMEs (Windapo \& Jedede 2013) and the very low level of awareness and knowledge of $H \& S$ requirements in small firms and among their owner-managers (Vickers et al. 2005).

Large construction firms have more funds and resources to allocate to H\&S than SMEs (Windapo \& Jedede 2013), thus it is likely that SMEs may employ less competent persons due to the lack of funds and resources. Legislation and/or regulatory frameworks that do not consider the sizes of firms pose challenges to small firms who already face difficulties in understanding H\&S requirements (Vickers et al. 2005). Earlier studies show that owners-managers of small businesses have a poor understanding of H\&S legislation and some do not take responsibility for H\&S in their organisations (Fonteyn et al. 1997). As a result, owner/managers of SMEs find it challenging to engage in H\&S (Kheni et al. 2007). 
Explanations as to involvement in H\&S should be seen in relation to the size of firms. There is evidence that owners/managers of SMEs in developing countries would engage in H\&S due to family values and culture (Kheni et al. 2007) and even in developed countries (Vickers et al. 2005). Large firms would rather engage in H\&S because of their social and business reputation, regardless of the cost implications (Wright 1998). The labour intensive characteristics of the industry (Kheni et al. 2007) may mean that only large firms would adopt mechanised construction because they have the funds. Consequently, efforts to improve H\&S, which do not categorically address the industry in the capacity of their sizes (large, small, and medium), may not be effective.

\section{The concept of self-regulation}

Tolerant, flexible and open regulatory approaches such as self-regulation is reported to have evolved due to the failure of deterrence-based strategies, command and control, regulation to achieve the desired results (Aalders \& Wilthagen 1997; Fairman \& Yapp 2005; Hutter \& Amodu 2008). Unlike command and control which is based on the regulator (state) setting policies and/or standards and ensuring compliance through the use of punitive measures (Aalders \& Wilthagen 1997, Havinga 2006; Hutter \& Amodu 2008), self-regulation relies on the involvement of the regulated to gain compliance. Self-regulation is viewed as being able to achieve a higher level of compliance, and is considered a less expensive regulatory approach compared to command and control (Anderson \& Russell 2011). Other points in favour of selfregulation are that it involves the regulated in the regulatory activities thus may give the regulated a sense of involvement making them view the legislative process as legitimate. However, according to Watterson, while flexible regulation can provide improved H\&S services, on the other hand, it can result in poorer H\&S practices (2006). For example, there are indications in Wright (1998) of small firms being disadvantaged on H\&S self-regulation because it is not prescriptive. Additionally, there are issues of accountability and transparency in self-regulatory programs (Bartle \&Vass 2005) and inability to perform up to expectation (Bartle \& Vass 2005; Gunningham 2011).

\section{Regulation of health and safety in the Nigerian construction industry}

It has been argued that construction sites and construction activities in Nigeria are not covered by the Factories Act F1 LFN 2004, the local H\&S legislation, thus the construction industry is unregulated (Diugwu et al. 2012, Idoro 2011, cf. Umeokafor et al. 2014). As a result, construction contractors adopt H\&S legislation and standards from developed countries (Idoro 2008, 2011; Tanko \& Anigbogu 2012), thus implementation and administration are left to the construction contractors (Idoro 2008). This is additional to the contractors, inter alia, practitioners in various states of Nigeria that adopt the local National building Code of 2006 despite the fact that it is yet to receive legislative approval (Omeife \& Windapo 2013) at the time of writing this paper. The National building Code of 2006 is designed to address some of the H\&S challenges in the building industry by providing minimum standards. The aforesaid practice by these contractors is arguably one form of self-regulation (Gunningham 2011; Havinga 2006; King \& Lenox 2000) but the quality is a different issue. It can, therefore, be argued that the construction industry is unregulated by the state but self-regulated. 
Umeokafor and Isaac (2015) have argued that the Nigerian construction industry is indirectly externally regulated. In particular, it can be argued that the International Labour Organisation (ILO) standard (Occupational Safety and Health Convention, 1981 NO 155) covers the construction industry. Typically, Nigeria has ratified the ILO convention and paragraph 1 article 16 of the convention requires employers to so far as it is reasonably practicable ensure that the workplaces, equipment, work processes and all machinery therein are safe, posing no risk to the health of the workers. Paragraph 3 of article 16 of the convention also states measures that employers should take to prevent people from harm. However, the legal system in Nigeria is dualist. International laws and instruments are perceived as different from local laws and the international instruments will need to be judicially accepted at the local level for it to be effective (Okene 2009). In other words, the international instruments such as Occupational Safety and Health Convention, 1981 NO 155 of the ILO will not be automatically accepted in the legal system of Nigeria until it goes through some judicial processes. Nonetheless, Okene (2009) offers optimism in that he demonstrates how local courts can indirectly use international instruments for interpretation of local laws (also see Umeokafor \& Isaac 2015). Authors also go on to argue that international instruments can also be indirectly used as a reference (for example Okene 2009; Umeokafor \& Isaac 2015). International instruments can be used in situations where the local law has anomalies (Umeokafor \& Isaac 2015). Consequently, it can be argued that the Nigerian construction industry is indirectly legally covered as per H\&S, as Nigeria is bound by ILO standards. However, in practice it may not be so. In practice, the ILO standard may not be recognised or may not be effective, besides the Factories Act 2004, which is the local legislation, is yet to be adhered to.

Contractors with head offices outside Nigeria may be bound by the H\&S laws or company policies where H\&S laws are sound and/or where the legal system is not dualist. They may by default, be regulated by the parent company and/or the H\&S laws in their countries of origin or even the international instruments. Nonetheless, irrespective of the side of the argument that holds, some contractors can be argued to engage in self-regulation (Umeokafor \& Isaac 2015) and/or the H\&S regulatory environment of Nigeria's construction industry may be viewed as complex. Additionally, the various adopted H\&S legislation and standards from various countries, which present different regulatory approaches, and different nature of legislation (i.e., prescriptive legislation or goal based legislation) also contribute to the argument that construction $\mathrm{H} \& \mathrm{~S}$ regulation in Nigeria is complex. Consequently, to advance the study, the possible self-regulatory approaches that obtain in Nigeria's construction industry are identified and discussed. The drivers and motivators are then identified, assessed and explained.

\section{Relating self-regulatory approaches to the Nigerian construction industry}

Considering the description of self-regulation below, Umeokafor and Isaac (2015) demonstrate that three or four H\&S self-regulatory categories exist in the Nigerian construction industry;

1. Industry self-regulation. This is the process whereby the regulatory activities of the industry are overseen by the members of the industry or industry association or professional bodies (Finger \& Gamper-Rabindran 2013; Havinga 2006; Hutter 2006). 
They design or adopt standards and administer them, controlling the activities of their members (Finger \& Gamper-Rabindran 2013; Havinga 2006; King \& Lenox 2000). Membership or involvement in industry self-regulation may be voluntary or a prerequisite for operating in the industry. As this is the case, arguments can be made that some parts of the Nigerian construction industry operate under this category of self-regulation. Specifically, the construction sector in the oil and gas industry is regulated by the oil and gas industry that sets and enforces standards that all contractors that work for them must adhere to. These standards are a prerequisite for contractors to work in the industry. This can be argued to be industry enforced selfregulation or industry mandatory self-regulation (used interchangeably in this paper).

2. Client-led self-regulation. This is where the client requires the contractors to adhere to H\&S standards. The client can set and administer the standards or the client can specify that the construction contractors adhere to international standards. For example, Kheni et al. (2007) report that some international organisations in developing countries require their contractors to meet international H\&S standards. If this is the case, then client-led self-regulation occurs in the Nigerian construction industry. Client-led self-regulation may have a contractual backing thus enforceable.

3. Pure self-regulation. According to Gunningham (2011), this occurs when the regulated voluntarily designs or adopts standards, and/or international instruments and administer them. Although this is rare (Aalders \& Wilthagen, 1997), it happens. Going by the arguments by authors (Idoro 2011; Tanko \& Anigbogu 2012) that Nigerian construction contractors adopt standards from developed countries, then pure self-regulation occurs in Nigeria. However, this can only be argued to occur if the argument that in practice the construction industry if not covered by any H\&S legislation holds.

4. Enforced self-regulation. If the argument that the ILO standards cover the Nigerian construction industry holds, then construction contractors that adopt standards from other countries can be argued to engage in enforced self-regulation. Even if the ILO standards argument above does not hold, but the argument of construction contractors adopting standards from other countries holds, it can be argued that construction contractors adopting standards because it is part of their overseas company policy where the parent company overseas is covered by any H\&S legislation engage in enforced self-regulation. Enforced self-regulation is the process whereby organisations or individuals design or adopt policies and administer them because it is a statutory requirement (see: Fairman \& Yapp 2005; Havinga 2006; Hutter \& Amodu, 2008; Hutter 2001). It can be argued that enforced self-regulation is compliance with the law. Based on the background established so far, self-regulation is conceptualised on a broad perspective.

\section{Identifying the determinants of health and safety self-regulation}

Various studies discuss self-regulation, but the framework for analysing the determinants of H\&S self-regulation in the Nigerian construction industry has been used for identifying the factors (Umeokafor \& Isaac 2015) (see Figure 1). This is not only because it has been designed for analysing the determinants of H\&S selfregulation in the developing countries construction, but also because it is believed to present what really happens in practice in Nigeria. 
Figure. 1: A proposed framework for analysing the determinants H\&S self-regulation. Source: Umeokafor and Isaac (2015)

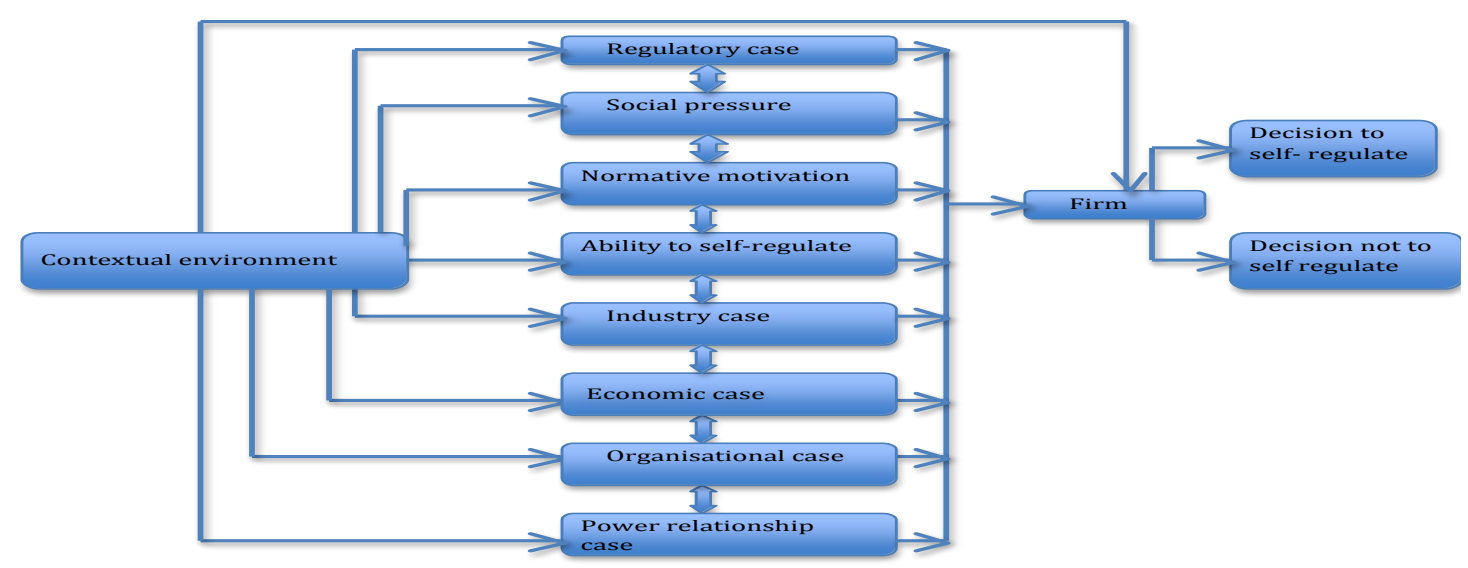

Umeokafor and Isaac (2015) propose a framework for analysing the determinants of H\&S self-regulation comprising: regulatory case, power relationship case, organisational case, economic case, normative motivation, the ability to self-regulate, industry case, social pressure. They demonstrate that contextual factors such as culture, religion, belief, inter alia, also impact on the overall element of the framework. Kheni et al. (2007) offer a treatise on the influence of culture, institutional arrangement, and politics on H\&S. It is, however, vital to note the factors assessed in this study may not the exhaustive list. The framework (Figure 1) is discussed below.

Social pressure

Citing Giuliano and Linder (2013), Nielsen (2003) and Levinson (1987), Umeokafor and Isaac (2015) demonstrate that pressure from social groups, lawsuits, trade unions, and employees can prompt organisations and/or the industry to self-regulate. This is supported by Gonzalez-Benito and Gonzalez-Benito (2005) who also note factors such as pressure from stakeholders. It is, however, possible that the impact of the social pressure can be negative. For example, there can be pressure from trade unions not to self-regulate for reasons such as viewing the legislation as legitimate. The point here is that organisations will succumb to social-related pressures.

\section{Economic case}

This is underpinned by the motive to make a profit and/or reduce the cost of production. Organisations weigh the risks of being apprehended and decide to selfregulate. This is based on the premise of deterrence theory (Umeokafor \& Isaac 2015). Consequently, factors such as calculated economic benefit of the organisation (Giuliano and Linder 2013; Laeeque et al 2006), fines (Kircher et al 2008), calculated benefits of good accident records, fear of damage to the reputation of the organisation (Umeokafor et al. 2014) resulting to economic loss, fall into this group.

Normative motivation 
This covers factors such as moral duty too comply (Fairman \& Yapp 2004) which, in this case, is the duty to self-regulate (Giuliano \& Linder 2013) because the legislation is considered to be legitimate (Giuliano and Linder 2013; c.f Winter \& May 2001) or because it is the right thing to do.

Organisational case

This covers factors that relate to the internal activities of the organisation, such as the value attached to H\&S (Gonzalez-Benito \& Gonzalez-Benito 2005) and the commitment of management (Umeokafor et al. 2014). Umeokafor et al. (2014) claim that these are internal factors that determine the direction of the decision to selfregulate, and that organisational culture is also a factor to consider in this case. Factors in Table 3 such as the scope of operation of the organisation and high level of management commitment can be classified under this.

Industry case

According to Gonzalez-Benito and Gonzalez-Benito (2005) the factors that determine self-regulation include the industry sector and the geographical location of the organisation. In the Nigerian oil producing areas context is a key factor in that the market determines self-regulation; described as industry self-regulation above (see Table 3). As much as these factors can be considered as pressure from the market, it can also suggest that there can be pressure from competitors in the market or supply chain, prompting self-regulation. It is also possible that the impact of these factors can be barriers (in terms of normative case \& industry case), for example, if the industry does not agree with the legislation, they may pressure organisations not to selfregulate. Also, the pressure from the members of the construction supply chain can be aimed at ensuring the organisation do not self-regulate.

\section{Regulatory case}

The threat from regulation is another factor that Giuliano and Linder (2013) cover. Other factors in this category include: self-regulation because of the activities of the regulator, the level of organisation's involvement in H\&S regulatory activities inter alia. Umeokafor and Isaac (2015) claim that the regulated will self-regulate if they are part of the regulatory activities, suggesting that the higher the external involvement, the more likely the regulated are not to self-regulate. Adequate legislation, legitimate legislation, legitimate regulatory process, inter alia, can also drive self-regulation. A better understanding of the legislation can also be grouped under the regulatory case as can be seen in 'the ability to self-regulate'.

Ability to self-regulate

Building on the premise of authors such as Nielsen (2003) and Winter and May (2001), Umeokafor and Isaac (2015) demonstrate that this occurs when the regulated is willing to self-regulate, but factors such as lack of funds, inadequate legislation lack of knowledge hinder them. In contrast, availability of funds, good understanding of the benefits of self-regulation or the legislation can increase the ability of the construction contractors to self-regulate.

Power relationship

Although this may rarely be a driver, it is mostly a barrier. In this case the contractors consider their ability to influence the events or activities in the society. If they are able to resist opposition or influence the regulator's decision, they will not self- 
regulate (Umeokafor \& Isaac 2015). Factors such as influence in the society, and financial power are considerations.

\section{RESEARCH METHODOLOGY}

This research sought to identify, assess and explain the H\&S self-regulatory approaches and the drivers and motivators of H\&S self-regulation in the Nigerian construction industry. A literature survey was conducted and 32 key H\&S selfregulatory drivers and motivators were identified. This was based on the tool (figure 1) for analysing the determinants of H\&S self-regulation in the Nigerian construction industry, which has been validated by experts and academics (Umeokafor \& Isaac 2015).

\section{Sampling and primary data collection}

Mixed methods research, involving quantitative and qualitative methods was adopted. The H\&S self-regulatory approaches, the drivers, and motivators of H\&S selfregulation were identified and assessed through quantitative survey. Interviews were conducted to help collaborate and enhanced the quantitative findings. Epistemologically, mixed methods research has been praised for its ability to offer richer insight into social phenomena (Denzin 1978). This is because of the ability of the methods to triangulate each other, demonstrating their complementary strengths and improving reliability and validity (cf. Alonso \& Barredo 2013).

Based on the literature survey, questionnaires were designed, piloted and revised. Non-probability purposeful sampling was adopted where the criteria set include that the respondents must have H\&S responsibilities and must be involved in H\&S selfregulation. This is because $H \& S$ expertise and/or experience are needed to address the research questions. For the academics to participate in the research, in addition to the academic positions they hold, they had to be actively involved in construction practices with H\&S responsibilities. This may be on a part-time basis where they run a private construction practice or employed by a construction firm on part-time basis. Alternatively, the academic position can be on a part-time basis and the construction practice full-time.

H\&S self-regulation is not commonplace in the Nigerian construction industry and this affected the number of potential respondents. Furthermore, there is no comprehensive list of construction practitioners with H\&S responsibility in Nigeria. Fifty questionnaires were self-administered to construction practitioners (who met the criteria for participation in the research) in Abuja, Lokoja, Enugu, Afikpo, Awka, Port Harcourt, Kaduna and Lagos states by research assistants. There are six geopolitical zones in Nigeria and all but one (North East) was covered due to the unrest in that area of the country as at the time of data collection. The sample included: engineers, project managers, architects, H\&S managers, and quantity surveyors. Thirty-nine questionnaires were returned, but two were discarded because they were not properly completed. Thus, thirty-seven questionnaires were used for this study, giving a 74 percent response rate. The sample was made up of macro and small-scale firms with 1 - 29 employees; medium scale firms with 30 - 199 employees of and large firms with employees of 200 and above (Kheni et al. 2008). 
For the interviews, purposeful sampling technique was adopted where 16 construction professionals such as architects, builders, H\&S practitioners, and quantity surveyors from large, medium and small-scale organisations were involved. The aim was that the interviewees would have $\mathrm{H} \& \mathrm{~S}$ responsibilities and well experienced in terms of $H \& S$ in the industry, preferably from a self-regulatory perspective. These interviews in supplementing the questionnaires also provided a deeper insight into the phenomena, advancing the understanding of the various types of H\&S self-regulation in the Nigeria construction industry and their determinants.

Although this is scoping study, it is necessary to highlight some points about the small quantitative sample. Some schools of thought still argue that it is naive to draw strong conclusions based on the small quantitative sample. First, it is important to remember that the criteria for participation have already limited the number of prospective respondents. Second, just like religion, $H \& S$ is a very sensitive topic in Nigeria, especially in the construction industry and this makes the collection of data challenging. Third, if there was adequate funding for the research it may have been possible to increase the size of the quantitative sample. However, the author believes that the findings may not significantly differ from the output of a larger sample. Studies of small samples can make a valuable contribution to knowledge. Studies with small quantitative samples can be viewed as making an astronomical observation with binoculars, thus the small sample does not mean that statistical studies cannot be conducted (Sauro 2013). This is a scoping study, thus the findings can be considered as indicative of the current situation in Nigeria. However, the findings do contribute to knowledge given a dearth of H\&S literature and statistics in developing countries (Puplampu \& Quartey 2012). The findings may also be used as a basis for further work.

\section{Data collection instruments}

The first part of the questionnaire examined the profile of the respondents and the second part examined the H\&S self-regulatory approach in Nigeria, where some of the questions were in nominal scale. The last section examined the determinants of H\&S self-regulation in the Nigerian construction industry. Respondents were asked to rank the factors in a Likert scale of 1 to 5 where ' 1 ' is strongly disagree to ' 5 ', strongly agree. A Cronbach Alpha test was conduced to test the reliability of the instrument where a value of .991 was found, suggesting an acceptable reliability level of the instrument. The interview guide was piloted to six construction professionals, including H\&S experts, and revised based on their feedback. Prior to conducting the interviews, the H\&S knowledge of the interviewees was assessed and if found adequate, the interview went ahead. Questions were semi-structured and were designed based on the tool for analysing the determinants of H\&S self-regulation in the Nigerian construction industry (Umeokafor \& Isaac 2015).

\section{Data analysis}

The quantitative data was analysed with Statistical Package for Social Science (SPSS) software, where descriptive and inferential statistics were employed. Data are presented in frequency and the mean statistics of the factors identified. In terms of inferential statistics, Kruskal-Willos H test and Chi-square were also employed. The framework for analysing the determinants of $H \& S$ self-regulation (Figure 1) was also used in the discussion of results. The non-parametric test was conducted because the data did not meet the requirements for a parametric test. The qualitative data was 
analysed thematically with the software NVivo for mac. Analysis involved group analysis encompassing categories of construction firms, namely, large, medium and small-scale firms. The quantitative and qualitative data were analysed in a convergent manner, triangulating each other and at the same time explaining the phenomena.

\section{RESULTS AND DISCUSSION \\ Demographic profile of respondents}

Ten of the respondents (a little over one quarter) were from small-scale firms, 15 (a little below half) from medium-scale firms and 12 (over three quarter) from largescale firms. The scope of operation of 5 firms is multinational, 18 (a little below half) of the firms national, 5 firms regional, and 9 (almost one quarter) were local. Of the 30 respondents that have more than 5 years of work experience, 18 (almost half) had over 21 years of work experience. Eighteen of the respondents had only graduate degree or equivalent, while 19 (a half) had post-graduate degrees. The designation of the respondents covered academics and practitioners, comprising 3 lectures, 2 safety officers, 9 project managers, 2 architects, 8 civil engineers, 6 builders, 5 quantity surveyors, 1 head of labour and 1 town planner.

In terms of the interviewees, 5 were from large-scale firms, 6 were from medium scale firms and 5 were from small-scale firms. They all had a minimum of first degree or equivalent and have worked in the construction industry for at least 6 years.

\section{Self-regulatory approaches in the Nigerian construction industry}

Self-regulation varies from country to country (Hutter, 2006), so Table 1 presents it from the Nigerian perspective. The objective axiology (that is the value the researcher attaches to knowledge) evidenced in Table 1 is questionable. This is because below a quarter (6) of the respondents claimed not to engage in any type of H\&S selfregulatory approaches. However, the interviews helped to highlight another possible type of H\&S self-regulation, community-led H\&S self-regulation. Interviewees narrated how communities required that they set standards and even contribute to setting the scope of the standards. These communities have appointed persons that work with these firms to set these standards and ensure that they are enforced. The communities are well involved in the regulatory process that they even stipulate the number of workers from their communities that the construction firms must employ. If the construction firms refuse to work 'hand in hand' with the communities in the regulatory process, the communities take the laws into their hands, perhaps, through demonstration or obstructing construction. This type of regulation is classed in this study as 'community-led self-regulation' and communities have a strong influence on $\mathrm{H} \& \mathrm{~S}$, especially as it relates to the environmental safety.

Table 1: Possible Self-regulatory approaches in the Nigerian construction industry

\begin{tabular}{|c|c|c|c|c|}
\hline \multirow{2}{*}{$\begin{array}{l}\text { Types of } \\
\text { Self-regulation }\end{array}$} & Small scale & Medium scale & Large scale & Total \\
\hline & Frequency & Frequency & Frequency & Frequency \\
\hline Enforced & 1 & 7 & 2 & 10 \\
\hline Pure & 4 & 3 & 4 & 11 \\
\hline Industry enforced & 1 & 3 & - & 4 \\
\hline Industry & - & - & 3 & 3 \\
\hline Client led & 2 & 1 & - & 3 \\
\hline None of the above & 2 & 1 & 3 & 6 \\
\hline
\end{tabular}


\begin{tabular}{lllll}
\hline Total & 10 & 15 & 12 & 37
\end{tabular}

In contrast, 11 of the respondents claimed that their organisations voluntarily selfregulate. It is supported by the 'voluntary' adoption of H\&S laws or programs by construction contractors in Nigeria from developed countries (Diugwu et al 2012; Idoro 2008, 2011). It also appears to be consistent with the results in Table 3, which shows the first three highest ranked drivers and motivators of H\&S self-regulation to be pure self-regulatory-oriented. Client led and industry self-regulation rank the same in Table 1, with both having 3 respondents each (i.e. below a quarter of the respondents). This is further interrogated in Table 2.

In terms of the various self-regulatory approaches among the various categories of construction contractors in Nigeria (Table 1), it is evident from Table 1 that pure selfregulation is mostly adopted in small-scale firms, 4 (below half of the small firms) and large scale firms, 4 (over one quarter of the large firms). Conversely, enforced self-regulation is mostly adopted in medium scale firms, 7 (approximately half of the medium-scale firms). This is, however, inconsistent with the description of enforced self-regulation in the literature review section, but the findings of the interviews in the paragraph below explain better. Contrary to expectation, large-scale firms, 2 (a little below one quarter of the large firms) do not engage in any of the self-regulatory approaches in Table 1.

Evidence from the interviews helps to explain these answers. Typically, all the respondents from small-scale firms noted that they self-regulate voluntarily or if the clients require it. Respondents from medium-scale firms noted that in many cases, the standards they adhered to are set by the large firms or by the oil and gas sector who also enforce and monitor the standards. Some of these respondents from mediumscale firms further explained that these H\&S standards, programs or policies set by the large firms are from developed countries such as UK; thus, as long as they work for these large firms, they are bound these standards, programs or policies. Therefore, it is logical to state that these medium-scale firms are involved in enforced selfregulation, sometimes. This explains the inconsistency in the definition of enforced self-regulation and the survey findings in the above paragraph. This is consistent with the quantitative findings (Table 1). If this is the case, then in the context of Nigeria, it is possible to extend the definition of enforced self-regulation, covering when medium-scale construction firms are enforced to self-regulate by individual large construction firms who engage in enforced self-regulation (see the description of enforced self-regulation noted elsewhere in this paper.). In terms of the large firms, in contrast to Table 1 where they claim to engage in pure self-regulation, evidence from the interviews suggests that they do not voluntarily self-regulate. Rather these large firms have standards from their parent companies or countries that they have to adhere to - enforced self-regulation. They also understand the benefits of H\&S selfregulation such as economic benefits, increased productivity, which make them selfregulate. The inconsistency in the survey and interview findings requires further research. However, it may be explained by the fact that construction contractors are not legally obliged by the local H\&S laws to self-regulate, so they may view their H\&S self-regulatory activities as voluntary even though they are bound to selfregulate by their parent company policy, in accordance with international H\&S laws. 
While the analysis of the statistical survey does not show cases where the respondents engage in more than two categories of $\mathrm{H} \& \mathrm{~S}$ self-regulation, the interviews suggest that some contractors fall into one or more categories. This can be explained by the fact that they may be involved in various projects at various stages, with different types of regulation and hence involved in self-regulation in one project and not in others.

\section{The perceived most effective self-regulatory approaches in Nigeria}

The study also sought to evaluate the perceived most effective self-regulatory approach between client-led self-regulation and industry mandatory self-regulation. Almost three quarters (27) of respondents claimed that client-led self-regulation could be more effective as a driver than industry mandatory self-regulation (see Table 2). This was significant among respondents from medium scale firms where 14 (the majority) view client-led self-regulation as more impactful as a driver than mandatory industry-led. Wright (1998) suggests that client-led H\&S self-regulation may be quite effective, as it is accorded equal attention as other clients' requirements. Kheni et al. (2007) report the influence of international clients in developing countries in that in some cases they make H\&S mandatory. This may explain why there is now greater emphasis on client involvement in H\&S, such as the Construction Design and Management (CDM) regulations of 2015 (HSE 2015).

Table 2: Evaluation of most effective self-regulatory approach between client-led and industry mandatory self-regulation.

\begin{tabular}{lllll}
\hline Reponses & Small scale & Medium scale & Large scale & Total \\
\cline { 2 - 5 } & Frequency & Frequency & Frequency & Frequency \\
\hline Yes & 5 & 14 & 8 & 27 \\
No & 5 & 1 & 4 & 10 \\
\hline Total & 10 & 15 & 12 & 37 \\
\hline
\end{tabular}

Table 2 shows that small-scale contractors do not view any of the regulatory approaches to be more effective. Although Table 1 shows that large firms are not involved in client-led H\&S self-regulation, 8 of the respondents from the large-scale firms viewed client-led as more effective than industry mandatory H\&S selfregulation.

To further investigate if there is a relationship between category of the construction contractors, client-led self-regulation and industry mandatory self-regulation, a nonparametric chi-square test was conducted. A chi-square statistics of 6.0707 with a Pvalue of .048057 show that the result is significant as $p<0.05$. This simply means that it is unlikely that the variables are independent. Therefore, a relationship exists among categories of construction contractors, client-led self-regulation and industry mandatory self-regulation.

According to all interview respondents, once a client requires them to adhere to a set of standards they are obliged to adhere to them, or else they would lose their contracts. A few of the respondents from the large firms appear to explain why there is no record of client-led H\&S self-regulation in Table 1. They note that their clients 
may not really impact on $\mathrm{H} \& S$ self-regulation because they already have set (minimum) standards. One of the respondents suggested that because they have the financial strength and are among the few that can carry out specific types of projects in the country, they stand their ground if any prospective client wants the standard reduced. In contrast to the responses noted in Table 2 where there was no difference between client-led self-regulation and industry mandatory self-regulation for small firms, the interviewees from small firms viewed client-led self-regulation as more effective than industry self-regulation. However, this may be because, unlike medium- scale firms, they may not really be involved in industry self-regulatory projects.

\section{A comparison of the drivers and motivator of $H \& S$ self-regulation among large, medium and small-scale construction contractors.}

Table 3 shows that pure self-regulatory related factors rank the first three overall among the respondents. This tends to be in agreement with the result shown in Table 1 , where pure self-regulation is mostly adopted in the Nigerian construction industry. It is evident that normative motivations are perceived to explain the drivers and/or motivators of H\&S self-regulation (Figure 1). For example, 'adopting H\&S programs because it is the right thing to do' ranks first across the three categories, and first overall with an overall mean of 4.12 . Another normative factor, 'a duty to selfregulate' ranks third overall with a mean of 3.75. The interviews reinforced these findings. Some firms self-regulate because they viewed it 'as a duty to self-regulate' and that 'it is the right thing to do', i.e. a case of normative motivation. It also demonstrates strong leadership and management commitment to H\&S. One of the respondents stated:

"Before we start any work, as part of the Director of works' responsibilities, he would visit the site and if it is not safe, the work will not start. He would have a look at all the documents that we have, including the site safety plan, method statements and risk assessments, and ensure that they are ok. It is unfair to get our workers to the site if our managers do not consider it to be safe for a visit... I can remember when there were some issues with one community, (name withheld) where we had projects and with some scaffoldings there, the Director of works insisted that he would visit the site first, walk and inspect the scaffolds prior to the commencement of any work. We are all in this [H\&S] together so if the site is not safe for the director to visit or if the procedures are not robust enough to address $H \& S$, the work would not go ahead" [Senior project manager/civil engineer, medium scale firms].

Conversely, the legitimacy of legislation (Guiliano \& Linder 2013), which ranks 18th overall with a mean of above 2.5 is a normative explanation to self-regulation (Table 3 ), but may have ranked low because it is also a regulatory case related. Umeokafor (2015) found that regulatory related factors such as inadequate legislation significantly challenge $\mathrm{H} \& \mathrm{~S}$ practices in the Nigerian construction industry. Interviewees explained why the H\&S laws are viewed as illegitimate and how it is a barrier. One of the interviewees from a medium-scale firm suggested that they experience conflict in standards in that the guidelines issued by a building authority (name withheld) was incompatible with the H\&S standards and guidelines they adopted from developed countries. Similarly, one interviewee from a medium-scale firm and one from a small-scale firm noted that the guidelines, manuals etc. from the 
building authority are unfair, unrealistic and designed for monetary purposes and not for safety reasons. As a result, they viewed the laws as illegitimate.

It is also significant that medium and large firms view self-regulation as important because of the benefits, such as economic benefits, in that it ranks second in the medium and large firms and fourth in small firms. This economic benefit then ranks fourth overall with a mean of 3.59 (see Table 3). Another factor that will have economic implications on organisations is the fear that incidents may have a negative impact on the image of firms, which ranks fifth with the overall mean of 3.56 (Table 3). This may be considered to the consistent with the position of Wright (1998) who concludes that fear of adverse publicity is a motivator to H\&S in firms of all sizes of hazardous work environment.

The impact of social pressure is also ranked high with 'pressure from employees' (with the overall mean of 3.55) ranking $6^{\text {th }}$, and pressure from clients with the overall mean of 3.37 , ranking $8^{\text {th }}$ (Table 3 ). Importantly, the factor, 'pressure from clients' ranks low among large firms (that is 9th with a mean of 3.08) when compared to other categories. This may be because some large firms already have mandatory or high H\&S standards, so pressure from clients may not be significant. This is consistent with the interview findings in that pressure from the client as a driver and motivators of H\&S self-regulation was mostly emphasised by respondents from small and medium scale firms. Table 3 shows that the scope of operation and the high level of management commitment, organisational culture (organsational case) rank second among large firms with a mean 3.83 compared to small-scale firms and medium scale firms.

The interviews confirmed the high level of management commitment and the strong safety culture that drive H\&S self-regulation. Typically, many of the interviewees from the large firms affirmed that the high level of management commitment in their organisations results in the strong safety culture. Some of the respondents from the medium-scale firms claimed that when they are working for multinational firms this strong safety culture and commitment to H\&S had an impact on them. However, they also noted that the level of management commitment to H\&S in their firms may not be as high as that found in the large firms (based on the fact that they had also worked for, or with, large construction firms). The small firms lacked the capacity to meet the high level of management commitment to H\&S, according to the interviewees. The findings of Othman (2012) also offer some possible explanations to this discourse in that the quest to increase productivity or meet the deadline may reduce the level of management commitment to $\mathrm{H} \& \mathrm{~S}$. This is also consistent with the quest for economic benefits between medium and small firms, which have been noted above.

Regulatory case factors rank low (i.e. 21 and 23 overall) in table 3 with the highest mean of 3.00 for medium firms and the lowest mean of 2.50 for large firms. This is not surprising as studies demonstrate the poor regulatory system of Nigeria, for example, Idoro (2008) and Umeokafor et al. (2014). This suggests that regulatory issues may be barriers to H\&S self-regulation; a point collaborated by the interviewees. Almost all interviewees emphasised the regulatory related points such as adequate $H \& S$ laws and adequate enforcement from the state as prospective drivers of H\&S self-regulation, except pure self-regulation. Many of the respondents from the 
medium scale firms emphasised the regulatory impact of large construction firms or their clients.

Table 3: drivers and motivators of health and safety self-regulation

\begin{tabular}{|c|c|c|c|c|c|c|c|c|}
\hline \multirow{2}{*}{$\begin{array}{l}\text { Identified drivers and motivators of health and } \\
\text { safety (H\&S) self-regulation }\end{array}$} & \multicolumn{2}{|c|}{ Small scale } & \multicolumn{2}{|c|}{ Medium scale } & \multicolumn{2}{|c|}{ Large scale } & \multicolumn{2}{|c|}{ Overall mean } \\
\hline & Mean & Rank & Mean & Rank & Mean & Rank & Mean & Rank \\
\hline We adopt $\mathrm{H} \& \mathrm{~S}$ programs It is the right thing & 4.20 & 1 & 4.00 & 1 & 4.17 & 1 & 4.12 & 1 \\
\hline $\begin{array}{l}\text { We adopt or develop the standards because we } \\
\text { understand the importance of } \mathrm{H} \& \mathrm{~S}\end{array}$ & 3.60 & 4 & 3.87 & 2 & 3.83 & 2 & 3.77 & 2 \\
\hline It is a duty to adopt health and safety programs & 4.10 & 2 & 3.47 & 6 & 3.67 & 3 & 3.75 & 3 \\
\hline Organisational economic benefits & 3.40 & 6 & 3.53 & 5 & 3.83 & 2 & 3.59 & 4 \\
\hline Fear of damage of reputation of organisation. & 3.50 & 5 & 3.67 & 4 & 3.50 & 5 & 3.56 & 5 \\
\hline Pressure from employees & 3.60 & 4 & 3.73 & 3 & 3.33 & 6 & 3.55 & 6 \\
\hline Calculated benefits on reputation of firm & 3.70 & 3 & 3.40 & 7 & 3.33 & 6 & 3.48 & 7 \\
\hline Pressure from clients to adopt H\&S policies & 3.50 & 6 & 3.53 & 5 & 3.08 & 9 & 3.37 & 8 \\
\hline $\begin{array}{l}\text { The scope of operation of our organisation eg. } \\
\text { large projects }\end{array}$ & 3.20 & 8 & 3.13 & 10 & 3.83 & 2 & 3.39 & 9 \\
\hline It is our organisational culture & 3.30 & 7 & 2.93 & 13 & 3.83 & 2 & 3.35 & 10 \\
\hline Calculated benefit of good accident records. & 3.40 & 6 & 3.33 & 8 & 3.25 & 7 & 3.33 & 11 \\
\hline High level of management commitment & 3.20 & 8 & 2.93 & 13 & 3.83 & 2 & 3.32 & 12 \\
\hline It is our organisational norms and values & 3.50 & 5 & 2.67 & 16 & 3.58 & 4 & 3.25 & 13 \\
\hline $\begin{array}{l}\text { High level of organisational involvement in } \\
\text { regulatory activities }\end{array}$ & 3.50 & 5 & 3.13 & 10 & 3.08 & 9 & 3.24 & 14 \\
\hline $\begin{array}{l}\text { Pressure from stakeholders in the organisation } \\
\text { to adopt health and safety polices }\end{array}$ & 3.40 & 6 & 3.07 & 11 & 3.17 & 8 & 3.21 & 15 \\
\hline $\begin{array}{l}\text { We adopt or develop H\&S standards because it } \\
\text { is a minimum requirement from our clients }\end{array}$ & 2.70 & 12 & 3.33 & 8 & 2.92 & 11 & 2.98 & 16 \\
\hline $\begin{array}{l}\text { Pressure from members of the construction } \\
\text { supply chain }\end{array}$ & 3.10 & 9 & 3.13 & 10 & 2.67 & 13 & 2.97 & 17 \\
\hline $\begin{array}{l}\text { We adopt or develop the standards because it is } \\
\text { a minimum requirement in the industry }\end{array}$ & 2.60 & 13 & 3.40 & 7 & 2.92 & 11 & 2.97 & 17 \\
\hline The legislation is perceived to be fair & 2.80 & 11 & 3.07 & 11 & 3.0 & 10 & 2.96 & 18 \\
\hline Pressure from trade union & 3.20 & 8 & 3.07 & 11 & 2.42 & 16 & 2.90 & 19 \\
\hline High competitive pressure in the market & 2.80 & 11 & 2.87 & 14 & 3.00 & 10 & 2.90 & 19 \\
\hline $\begin{array}{l}\text { Pressure from pressure groups to adopt } \mathrm{H} \& \mathrm{~S} \\
\text { polices }\end{array}$ & 3.30 & 7 & 3.27 & 9 & 2.00 & 18 & 2.86 & 20 \\
\hline $\begin{array}{l}\text { We adopt or develop the standards because of } \\
\text { the efforts of the regulators of } \mathrm{H} \& S\end{array}$ & 2.60 & 13 & 3.13 & 10 & 2.75 & 12 & 2.83 & 21 \\
\hline $\begin{array}{l}\text { We adopt or develop the standards because of } \\
\text { the fear of prosecution }\end{array}$ & 2.80 & 11 & 3.00 & 12 & 2.67 & 13 & 2.83 & 21 \\
\hline Pressure due to lawsuits & 2.80 & 11 & 3.53 & 5 & 2.00 & 18 & 2.78 & 22 \\
\hline $\begin{array}{l}\text { The level of external involvement in regulatory } \\
\text { activities }\end{array}$ & 2.80 & 11 & 3.00 & 12 & 2.50 & 14 & 2.77 & 23 \\
\hline $\begin{array}{l}\text { Pressure from the industry to adopt } \mathrm{H} \& \mathrm{~S} \\
\text { polices }\end{array}$ & 3.10 & 9 & 2.73 & 15 & 2.50 & 14 & 2.78 & 24 \\
\hline Pressure from the media to adopt H\&S policies & 2.70 & 12 & 2.87 & 14 & 2.67 & 13 & 2.75 & 25 \\
\hline $\begin{array}{l}\text { The activities of the regulator of H\&S are } \\
\text { perceived to be fair }\end{array}$ & 2.90 & 10 & 2.30 & 17 & 2.92 & 11 & 2.71 & 26 \\
\hline Pressure from global market & 2.30 & 14 & 3.13 & 10 & 2.25 & 17 & 2.56 & 27 \\
\hline $\begin{array}{l}\text { We adopt or develop the standards because we } \\
\text { have the funds }\end{array}$ & 2.20 & 15 & 2.93 & 13 & 2.50 & 14 & 2.54 & 28 \\
\hline $\begin{array}{l}\text { We adopt or develop the standards because the } \\
\text { H\&S laws is not difficult to understand }\end{array}$ & 2.10 & 16 & 2.93 & 13 & 2.33 & 16 & 2.45 & 29 \\
\hline
\end{tabular}

Regulatory case (Figure 1) factors that rank $21^{\text {st }}$ and $23^{\text {rd }}$ overall in Table 3 are consistent with arguments of the poor H\&S regulatory environment in Nigeria. The findings from the interviews further advanced the understanding of the discourse beyond the drivers and motivators examined in the survey. There is evidence from the medium-scale firms and a few of the small-scale firms that the location of projects determines H\&S self-regulation. Nicely expressed by one of the respondents: 
"In my organisation, if we are working on projects in Lagos state, we do not use H\&S management systems such as OHSAS 18001 (Occupational Health and Safety Assessment Series), but if we are in Port Harcourt, we use OHSAS 18001 and complement it with other requirements in the oil and gas industry. We have standards and guidelines by the authorities in Lagos that we adhere to". [Quantity surveyor/Project manager of a medium-scale firm].

\section{Differences in the responses of large, medium and small sized construction contractors on the drivers and motivators of health and safety self-regulation in the construction industry}

Probing the results in Table 3 further to see if there are differences between the categories of construction contractors, the Kruskal-Willos $\mathrm{H}$ test showed that there are differences on only two factors. Firstly, there was a significant difference in the factor 'it is a duty to adopt H\&S programs' among the three categories with a $\mathrm{P}$ value of .001 . Then the post-hoc pairwise comparison of the categories contractors showed a difference between large construction firms and medium-sized firms with a significance value of .020 , and a difference between large construction firms and small-sized construction firms with a significance value of .001. Secondly, there was also a significance difference in the factor 'pressure from client to adopt H\&S policies' with a $\mathrm{P}$ value of 0.46 . However, the post-hoc pairwise comparison of the categories of contractors shows that there is no significant difference the category of contractors.

\section{CONCLUSIONS AND RECOMMENDATIONS}

This scoping study challenges the view that the Nigerian construction industry is unregulated by empirically evidencing the H\&S self-regulatory approaches in the industry namely, enforced, pure, industry enforced, industry, client-led, and community-led self-regulation. The findings advance the understanding of the drivers and/or motivators to the decision to self-regulate in terms of H\&S in the Nigerian construction industry by identifying, explaining and evidencing the impact of the factors on H\&S self-regulation. There is evidence of the strong presence of normative motivation to H\&S self-regulation such as 'adopting H\&S programs because it is the right thing to do', 'it is a duty to adopt H\&S programs' across all the three categories of the industry namely, large, medium and small firms. There is a significant difference between the categories of the industry on the factors 'it is a duty to adopt H\&S programs' and 'pressure from client to adopt H\&S policies'. This is supported by the highest number of the respondents that note that their organisations voluntarily self-regulate in terms of $H \& S$. This indicates that in the absence of effective H\&S regulation in the Nigerian construction industry and adequate state involvement, normative motivation remains an area that can be exploited for improving $H \& S$ in Nigeria if not in all developing countries. This is, of course, under the assumption that morality means the same to all in the industry.

Equally important is the finding that communities play a significant role in H\&S selfregulation in Nigeria, contributing with the setting of standards to enforcement and monitoring, alongside the contractors. Although it is unclear as to the extent that they are involved in the regulatory process, the concept of community-led regulation or a 
co-regulatory approach between the firm(s) and the community remains insightful, offering optimism to the H\&S discourse in developing countries. This approach to $H \& S$ self-regulation is encouraged, especially in the current absence of effective state involvement. Given that the H\&S regulatory environment in the Nigerian construction sector is fragmented and dysfunctional, there is evidence in this research of a clientled H\&S self-regulatory approach being more effective than industry H\&S selfregulation; a relationship existing between the client-led H\&S self-regulatory and industry enforced H\&S self-regulation and the three categories of the construction contractors.

Based on the findings it is tentatively recommended that dependence on the government to address H\&S issues through state regulatory means may not be helpful and other avenues should be explored. First, professional bodies or associations should consider the opportunities identified in this study. This could be through programs that educate the their members further on the moral justification for H\&S. Large construction firms can take similar steps and/or prioritise driving H\&S as they have a strong influence on medium-scale construction firms. Second, given the evidence of clients driving $H \& S$ self-regulation, which is perceived to be more effective than industry mandatory self-regulation, more responsibility should be bestowed on the clients (as other countries such as the UK have done). While Nigeria awaits H\&S laws that impose greater responsibilities on the clients, the local planning authorities that issue the building permits to clients should also hold clients responsible for H\&S. Third, communities that are involved in H\&S self-regulation can consider including industry associations or pressure groups or professional bodies in their framework of operation. Indeed, community-led H\&S self-regulation offers a new understanding of self-regulation and calls for further research, especially in developing countries.

Although the small quantitative sample makes statistical generalisation challenging, supported with the interviews the scoping study offers a unique insight into the discourse on H\&S. Therefore, the findings can be considered as indicative of the situation in Nigeria and thus serve as a basis for further research with larger quantitative samples.

\section{REFERENCES}

- Aalders, M., and Wilthagen, T. (1997). Moving Beyond Command-and control: reflectivity in the regulation of occupational safety and health and the environment. Law and Policy, 19 (4), 415- 443

- Alonso, M. O. and Barredo, D. (2013) International comparative studies: Towards the integration of qualitative methods. European Scientific Journal. 9 (17), $207-228$.

- Anderson, A. R. and Russell, E. O. (2011). Self-regulation: A strategic alternative for small firms? Journal of Business Strategy, 32 (4), 42- 47.

- Aniekwu, N. (2007). Accidents and Safety Violations in the Nigerian Construction Industry. Journal of Science and Technology, 27 (1), 81 - 89.

- Bartle, I. and Vass, P. (2005). Self-Regulation and the Regulatory State- A survey of Policy and Practice. Centre for the Study of Regulated Industries, University of Bath. Research Report 17. 
- Denzin, N.K. (1978). The research act: A theoretical introduction to sociological Methods. McGraw-Hill, New York.

- Diugwu I.A., Baba D. L., and Egila A. E. (2012). Effective Regulation and Level of Awareness: An Expose of the Nigeria's Construction Industry Open Journal of Safety Science and Technology, 2012, Vol. 2, 140-146.

- Fairman R. and Yapp, C. (2004). Compliance with food safety legislation in small and micro-businesses: enforcement as an external motivator. Journal of Environmental Health Research, 3, (2), 44-52.

- Fairman, R and Yapp, C (2005). Enforced self-regulation, prescription, and conceptions of compliance within small business: The impact of enforcement. Law and Policy, 27 (4), 491 - 519.

- Finger, S. R., and Gamper-Rabindran, S., (2013). Testing the effects of selfregulation on industrial accidents. Journal of Regulatory Economics, 43(43) 115-146

- Fonteyn, P., Olsberg, D. and Cross, J. A. (1997) Small business owner's knowledge of their occupational health and safety (OHS) legislative responsibilities. International Journal of Occupational Safety and Ergonomics, 3 (1-2) 41 - 57.

- Giuliano, G. and Linder, A. (2013) Motivations for self-regulation: The clean air action plan. Energy Policy 59, 513 - 522.

- Gonzalez-Benito, J. and Gonzalez-Benito, O. (2005). A review of factors of Environmental Proactivity. Business Strategy and the Environment, 15, 87102.

- Gunningham, N. (2011). Investigation of industry self-regulation in workplace health and safety in New Zealand. Gunningham \& Associates Pty Ltd. Retrieved on 20-11-13 from http://www.dol.govt.nz/whss/resources/investigation-industry-self-regulationwhss-nz.pdf

- Havinga, T. (2006). Private Regulation of Food and Safety by Supermarkets. 'Law and Policy', 28 (4), 516- 533.

- Health and safety executive (HSE) (2015). Managing health and safety in construction: Construction Design and Management. Retrieved on 06-10-15 from http://www.hse.gov.uk/pubns/priced/1153.pdf

- Hutter, B. (2001) Is enforced self-regulation a form of risk taking?: The case of railway health and safety 'International Journal of the Sociology of Law', $29(4), 379-400$.

- Hutter, B. (2006). The role of non-state actors in regulation. Centre for analysis of risks and regulation, London school of Economics and political science, London UK.

- Hutter, B. M. and Amodu, T. (2008). Risk Regulation and Compliance: Food Safety in the UK. NCP.04219. London School of Economics and Political Science, London, UK.

- Idoro, G. I. (2008). Health and safety management efforts as correlates of performance in the Nigerian construction industry. Journal of Civil Engineering and Management. 14 (4) 277-285.

- Idoro, G. I. (2011). Comparing Occupational Health and Safety (OHS) Management efforts and Performance of Nigerian Construction Contractors. Journal of Construction in Developing Countries, 16 (2), 151-173 
- International Labour Organisation (ILO) C155 - Occupational Safety and Health Convention, 1981 (No. 155). Retrieved from http://www.ilo.org/dyn/normlex/en/f?p=NORMLEXPUB:12100:0::NO::P12100 ILO_CODE:C155

- Kirchler, E., Hoelzl, E. and Wahl, I. (2008). Enforced versus voluntary tax compliance: The 'slippery slope' framework. Journal of Economic Psychology, 29, 210 - 225.

- Kheni, N. A., Dainty, A. R. J. and Gibb, A. G. F. (2007). Influence of political and socio-cultural environments on health and safety management within SMEs: A Ghana case study. In: Boyd, D (Ed) Procs, $23^{\text {rd }}$ Annual ARCOM Conference, 3-5 September 2007, Belfast, UK, Association of Researchers in Construction Management, 159-168.

- Kheni, N. A. (2008). Impact of health and safety management on safety performance of small and medium-sized construction business in Ghana (Doctoral Thesis Loughborough University). Retrieved from https://dspace.lboro.ac.uk/dspacejspui/bitstream/2134/4079/3/Kheni\%27s\%20PhD.pdf

- King, A. A., and Lenox, M. J., (2000). Industry self-regulation without sanctions: The chemical industry's responsible care program. Academic of Management Journal 43 (4) 698-716

- Kingston-Howlett, J. (2001). Development of an Information-based Approach to self-regulation of health and safety in small firms (Contract Research Report 330/2001: Health and Safety Executive). Retrieved on 22-04-14 from http://www.hse.gov.uk/research/crr_pdf/2001/crr01330.pdf

- Laeeque, H., Boon, H., Kachan, N., Cohen, J. C., and D'Cruz, J. (2006). The Canadian Natural Health Products (NHP) Regulations: Industry Compliance Motivations. Advances Access Publication 4 (2), 257- 262

- Levinson, A. (1987). Self-regulation and health and safety. Employee Relations, 9 (4), 3-8

- Nielsen, J. R. (2003). An analytical framework for studying: compliance and legitimacy in fisheries management. Marine Policy 27 (5), 425- 435.

- Okene, O. V. C. (2009) Brining rights home: The status of internal legal instruments in Nigerian domestic law. Journal of Law, Practice and Procedure, $1(4) 12-31$.

- Omeife, C. A. and Windapo, O. A. (2013) The impact of national building code of professionalism. Procs. $43^{\text {rd }}$ builders conference/AGM, August $26^{\text {th }}$ $30^{\text {th }}, 2013$, Abuja, $1-12$

- Othman, A. A. E. (2012) A study of causes and effects of contractors' noncomplaince with the health and safety regulations in the South African construction industry. Architectural Engineering and Design Management, 8 (3), $180-191$.

- Puplampu, B. B. and Quartey, S. H. (2012). Key issues on occupational health and safety practices in Ghana: A Review. International Journal of Business and Social Science. Vol. 3(19), 151 - 156.

- Sauro, J. (2013) Best practices for using statistics on small sample size. Retrieved from www.measuringu.com/blog/small-n.php on $02-0516$

- Tanko, B. L. and Anigbogu, N. A. (2012). The use of personal protective equipment (PPE) on construction sites in Nigeria. In: Laryea, S, Agyepong, S A, Leiringer, R and Hughes, W (Ed.), 'Procs 4th West Africa Built 
Environment Research (WABER) Conference', 24-26 July 2012, Abuja, Nigeria, 1341-1348

- Umeokafor, N., Umeadi, B., and Isaac, D. (2014). Determinants of Compliance with Health and Safety regulations in Nigeria's Construction Industry. Journal of Construction Project Management and Innovation, 4 (S1) 882- 899.

- Umeokafor, N. I (2015). An assessment of the influence of contextual environment on health and safety practices in the Nigerian construction industry. Proc.: CIB W099 International Health and safety Conference: Benefitting Workers and Society through inherently safe construction, 10- 11 Sept. Northern Ireland, UK, 397 - 406

- Umeokafor, N. I., and Isaac, D. (2015). A framework for analysing the determinants of health and safety self-regulation in the construction industry. In Behm, M and McAleenan (Ed.), Proc.: CIB W099 International Health and safety Confernce: Benefitting Workers and Society through inherently safe construction, 10- 11 Sept. 2015, Northern Ireland, UK, 478 - 487

- Vickers, I., James, P., Smallbone, D. and Baldock, R. (2005), Understanding small firms responses to regulation: The case of workplace health and safety. Policy Studies, 26 (2) 149 - 169.

- Watterson, A. (2006). Regulation of occupational health and safety in the semiconductor industry: Enforcement problems and solutions. International Journal of environmental Health, 12, 72-80.

- Windapo, A. O. and Jegede, O. P. (2013). A study of heath, safety and environment (HSE) practices of Nigerian construction companies. 'The professional Builder', 4 (1), 92- 103.

- Winter, S. C. and May, P. J. (2001). Motivation for compliance with environmental regulations. Journal of Policy Analysis and Management, 20 (4) 675- 698.

- Wright, M. S. (1998) Factor motivating health and safety management, Health and Safety Executive (HSE) contract research report 179/1998, HSE Books. 